\title{
QUEM PODE FALAR SOBRE CIÊNCIA E TECNOLOGIA? AS VOZES AUTORIZADAS NO DISCURSO JORNALÍSTICO DE GALILEU E SUPERINTERESSANTE
}

\author{
CATARINA SCHNEIDER \\ Universidade Federal de Juiz de Fora (UFJF) \\ Juiz de Fora, Minas Gerais, Brasil \\ E-mail: schneidercatarina@gmail.com \\ MICHELE DA SILVA TAVARES \\ Universidade Federal de Minas Gerais (UFMG) \\ Belo Horizonte, Minas Gerais, Brasil \\ E-mail: micheletavaresjor@yahoo.com.br
}


QUEM PODE FALAR SOBRE CIÊNCIA E TECNOLOGIA? AS VOZES AUTORIZADAS NO DISCURSO JORNALÍSTICO DE GALILEU E SUPERINTERESSANTE

Resumo: Este artigo apresenta uma reflexão sobre a utilização das fontes especializadas e a presença de marcas de autoridade no discurso jornalístico das revistas Galileu e Superinterssante, na cobertura de temas relacionados à "Ciência e Tecnologia". A combinação metodológica de Análise de Conteúdo e da Análise Crítica de Discurso permitiu compreender o uso de tal estratégia de acessibilização de conteúdo da revista.

Palavras-chaves: Jornalismo científico; Divulgação científica; Poder de fala.

¿QUIÉN PUEDE HABLAR DE CIENCIA Y TECNOLOGÍA? LAS VOCES AUTORIZADAS EN EL DISCURSO PERIODÍSTICO DE GALILEU Y SUPERINTERESSANTE

Resumen: Este artículo presenta una reflexión sobre la utilización de fuentes especializadas y la presencia de las marcas de autoridad en el discurso periodístico de las revistas, Galileu y Superinterssante, en la cobertura de temas relacionados con "Ciencia y Tecnología”. La combinación metodológica de Análisis de los Contenidos y el Análisis Crítico del Discurso nos ha permitido entender el uso de la estrategia de hacer el contenido accesible en la revista. Palabras clave: Periodismo científico; Divulgación científica; Poder del habla.

WHO CAN TALK ABOUT SCIENCE AND TECHNOLOGY? THE AUTHORIZED VOICES IN GALILEU AND SUPERINTERESSANTE'S JOURNALISTIC DISCOURSES

Abstract: This article presents a reflection on the use of specialized sources and on the presence of authority marks' in the magazines Galileu and Superinterssante's journalistic discourse, in coverage of topics related to "Science and Technology". The methodological combination of Content Analysis and the Critical Discourse Analysis enabled us to understand the use of such strategy of making the content accessible.

Keywords: Scientific journalism; Science popularization; Power of speech. 


\section{INTRODUÇÃO}

As revistas Galileu e Superinteressante oferecem ao leitor curiosidades de temas variados, enfatizando, principalmente, aqueles que têm relação com a ciência. Elas apresentam o conteúdo num formato mais acessível, numa linguagem que interage com os leitores, trazendo os temas para a realidade deles, acessibilizando assuntos geralmente científicos e tecnológicos que, primeiramente, são restrito à poucos. Uma estratégia discursiva que visa a acessibilização do conteúdo nas reportagens é a convocação de fontes autorizadas. Assim, além de a revista tornar a informação científica mais próximo ao universo do leitor, essa também é uma forma de passar credibilidade para o público.

Este trabalho, portanto, propõe uma reflexão sobre a utilização das fontes especializadas e a presença de marcas de autoridade, que caracterizam as vozes autorizadas a falar no texto jornalístico das revistas Galileu e Superinteressante'.

Para melhor sistematização do trabalho, inicialmente apresentamos uma breve diferenciação conceitual entre as noções de "Jornalismo Científico" e "Divulgação Cientifica", buscando entender como é possível tornar um conteúdo relacionado à ciência e tecnologia acessível ao leitor não especializado, sobretudo destacando o papel das duas revistas nesse processo de divulgação de informação. Em seguida, destacamos uma discussão sobre os conceitos de "credibilidade" e "veracidade" do discurso, em que serão analisadas as estratégias discursivas das revistas e a convocação das fontes como marca de autoridade conferida ao discurso jornalístico. Além disso, também abordaremos a questão do poder de fala, focando nas revistas e na cobertura feita sobre ciência e tecnologia.

Do ponto de vista metodológico, optou-se pela Análise de Conteúdo, para identificar e quantificar as fontes especializadas nas matérias de capa analisadas, e depois, a utilização da Análise Crítica do Discurso, que possibilitou identificar no discurso jornalístico as marcas de autoridade que caracterizam as vozes autorizadas a falar e conferem ao texto credibilidade e veracidade. Por fim, apresentamos alguns resultados obtidos a partir da análise das matérias de capa das duas revistas.

1 Este artigo apresenta uma adaptação dos resultados obtidos no Trabalho de Conclusão de Curso (TCC) da autora, intitulado "O discurso científico nas revistas Superinteressante e Galileu”, para finalização do curso de Jornalismo na Universidade Federal de Sergipe, em 2013. 


\title{
2 JORNALISMO CIENTÍFICO X DIVULGAÇÃO CIENTÍFICA
}

Além de bastante semelhantes, os termos Jornalismo Científico e Divulgação Científica se cruzam: os dois têm o objetivo de tornar públicas informações sobre pesquisa científica e de popularizar a Ciência. Mas, é importante destacar que há uma linha tênue que distingue os significados.

É possível encontrar o Jornalismo Científico em áreas de todos os tipos, como saúde, política, economia, agricultura, já que ele se propõe a trazer de uma forma mais acessível, com linguagem mais simples, o que é descoberto, analisado e estudado nessas áreas. Ele tenta trazer ao público o que eles não poderiam acessar por conta própria, se dedicando a quem está fora da esfera da Ciência.

Portanto, tudo aquilo que é científico e é divulgado na mídia, seja ela impressa, televisiva ou radiofônica, é considerado Jornalismo Científico, já que o objetivo é informar o público leigo sobre Ciência, trazer reflexões e discussões atualizadas sobre o assunto, além de informar a sua relação com a sociedade.

Dessa forma, é possível afirmar que todo Jornalismo Científico é também uma Divulgação Científica, pois a divulgação busca expandir o conhecimento, seja ele destinado ao público leigo ou voltado para a academia. Porém, não é possível fazer essa afirmação inversamente, já que a Divulgação Científica é voltada para o desenvolvimento acadêmico. Então ela é transmitida em artigos, seminários, palestras e tudo que expande o conhecimento para quem já tem uma afinidade com ele. A linguagem aqui já é mais elaborada e não há tanto a preocupação de tornar o conhecimento acessível a leigos.

Segundo José Reis,

\begin{abstract}
a divulgação científica realiza duas funções que se completam: em primeiro lugar, a função de ensinar, suprindo ou ampliando a função da própria escola; em segundo lugar, a função de fomentar o ensino (REIS citado por KREINZ, 2000, p.72)
\end{abstract}

A Divulgação Científica não precisa ser feita por jornalistas, podendo ser realizada por acadêmicos, cientistas e estudiosos. Assim, a estrutura de um objeto de divulgação científica não é jornalística. Com tudo isso, a Divulgação Científica é uma forma mais ampla de se transmitir informações sobre Ciência e Tecnologia. 
Alguns autores da área, além de fazer a distinção entre Jornalismo Científico e Divulgação Científica, separam os termos "Difusão Científica" e "Disseminação Científica”. Segundo Bueno (2006) parte de um conceito amplo de difusão científica, sendo "todo e qualquer processo ou recurso utilizado para a veiculação de informações científicas e tecnológicas”. Depois ele define a disseminação científica voltada para um público de especialistas. O conceito também é dividido entre intrapares, quando a circulação da informação é feita entre especialistas da mesma área, e extrapares, que diz respeito a veiculação da ciência por especialistas que se situam fora da área de especialização do objeto. (BUENO citado por GRILLO, 2006).

É importante chamar atenção para o caso dos artigos publicados em jornais ou revistas. Esse seria titulado como Jornalismo Científico, por está sendo veiculado na mídia. Porém, como é uma matéria escrita, na maioria das vezes, por um especialista, ela passa a ser definida como Divulgação Científica, mesmo que o autor traga para mais próximo do leitor a linguagem utilizada para explicar o assunto.

\section{1 Acessibilização do conteúdo}

Segundo Sérgio Villas Boas (2005), a importância dada à popularização da Ciência ampliou-se, consideravelmente, devido a alguns fatores que se concretizaram na sociedade, como a necessidade do entendimento social dos impactos da ciência e tecnologia na vida cotidiana e a necessidade da ciência dar soluções aos problemas básicos da humanidade. Com isso houve um crescimento significativo da produção científica, e assim, a necessidade de traduzir o que estava sendo descoberto para a sociedade não-científica.

Foi a partir dos resultados proposto pela ciência e tecnologia que a sociedade pode, assim, evoluir nos seus conhecimentos e na forma de se estruturar culturalmente a partir do momento que leva para a humanidade novas descobertas. Contudo, essa evolução só é possível quando as informações geradas através das áreas científicas chegam à sociedade de forma acessível, para que esta possa compreender quais os benefícios que determinadas descobertas trarão.

Para que isso seja possível, os meios de comunicação têm um papel essencial, pois eles são capazes de disseminar o que está acontecendo no mundo. Por isso, o jornalismo é, hoje, uma das grandes áreas da humanidade, pois é ele que passa de forma mais acessível os assuntos que a sociedade busca entender. $O$ jornalismo, seja ele na televisão, jornal, rádio, revistas ou 
internet, é a fonte principal para que a sociedade tenha acesso às conquistas da Ciência e da Tecnologia.

Diante disso, a mídia tem recebido maior atenção da literatura especializada. O Jornalismo Científico diz respeito a todas as ciências e tem uma relação estreita com os outros tipos de "jornalismo", como o político e econômico, por exemplo. Portanto, ele tem o objetivo de servir de consciência social, e uma das tarefas mais difíceis, é alcançar um equilíbrio entre o entusiasmo da Ciência e evitar transmitir uma visão exagerada dela, sabendo que na Ciência há erros, e isso permite que quem receba a informação crie seu próprio senso crítico. Assim, a acessibilização de conteúdos antes considerados restritos à um grupo específico de estudiosos se tornou um grande marco para o jornalismo e também para a evolução da humanidade.

\subsection{Revistas especializadas}

As revistas utilizadas neste estudo, Galileu e Superinteressante, têm como objetivo divulgar acontecimentos que são, à primeira vista, de conhecimento restrito, para que seja acessibilizado para o público em geral. Temas como Ciência, Tecnologia, Saúde e Comportamento são os mais publicados nos periódicos.

As duas revistas além de utilizarem estratégias para que o discurso torne-se mais próximo ao leitor, usam infográficos e imagens a fim de aumentar a compreensão de quem lê. Os periódicos têm o jovem-adulto como seu público alvo, geralmente da classe A e B, pretendendo antecipar o leitor de tudo aquilo que o conhecimento humano pretende produzir no futuro e que irá interferir na vida da sociedade em geral.

A escolha das duas revistas se deu a partir de suas semelhanças: elas são da mesma linha editorial- já que se propõem a trabalhar a Ciência, são voltadas para o mesmo público, têm propostas semelhantes e se apresentam de forma análoga.

O periódico Superinteressante, que está no mercado desde 1987, teve 150 mil exemplares na primeira edição. Com o passar dos anos, especificamente em 1995, a Super foi submetida à reformas no seu projeto gráfico para que aprimorasse a interação com o leitor. Em 1990, a revista começou a trazer temas como religião, paranormalidade e filosofia para suas pautas, inovando e se consagrando ainda mais no mercado. Assim, é possível notar que fatos científicos estão presentes em vários temas, sejam eles de saúde, social ou religioso, com o objetivo de desmistificar a ciência para o público. 
A revista Galileu foi publicada pela editora Abril em 1991, com uma matéria de capa sobre robôs-insetos, deixando claro o seu interesse em divulgar ciência e tecnologia. Em 1998, o periódico também passou por reformas no layout, pois a preocupação era o leitor, como as matérias estavam sendo escritas e como os consumidores reagiam a elas. Com o passar do tempo, essa preocupação só aumentou e outras estratégias passaram a ser usadas pelas revistas.

\section{ESTRATÉGIAS DISCURSIVAS}

O discurso jornalístico é regulado e regulador na sociedade com o seu poder de dizer a verdade sobre o mundo. Dessa forma, ele mantém uma atitude de confiança com o público que lhe também lhe concede esse atributo. De acordo com Benetti, Storch e Finatto (2011), esse laço de confiança sustenta o dispositivo de autoridade afirmado por "sou jornalista, e deste lugar posso falar" (BENETTI; STORCH; FINATTO, 2011, p. 68), colocando em sua mão o poder de fala e de verdade.

A revista, por exemplo, tem marcas discursivas que ressaltam o dispositivo de autoridade em alguns elementos, como o ethos da revista, ou seja, o que ela passa, o que ela quer que o outro pense sobre ela, acredite que ela é e de como quer ser vista. A segunda marca é afirmada pelo trabalho jornalístico, ou seja, o jornalista é autorizado a falar porque ele que apurou, fez entrevista, sabe o que é novo, porque estava no momento, porque estudou o tema, elaborou a pauta, dominando, assim, a técnica e competências particulares para isso.

Para ter autoridade ao falar, o jornalista precisa recorrer a campos especializados para criar o efeito de legitimidade e de distanciamento. Para isso ele recorre à fonte mais especializada e assim consegue esses dois atributos jornalísticos, pois procurou o melhor especialista para tratar daquele assunto e porque não se trata da opinião dele, portanto faz jus à imparcialidade, traz precisão, sabendo assim o que é científico e de relevância.

A noção de "verdade" é o que todos os meios de comunicação e órgãos de poder se propõem a aplicar perante a sociedade. Mas o discurso é passível de interdições de sua fala e revela, a partir daí, a sua ligação entre poder e desejo de verdade. Dessa forma, para que o discurso analisado nas revistas esteja no contexto de verdade e, além disso, torne-se mais acessível ao público, é preciso utilizar algumas estratégias discursivas como poder de fala, autoridade e valor de verdade. 
Para o jornalismo, esse desejo de verdade e objetividade está entre os delineadores éticos da profissão. Assim, os veículos jornalísticos oferecem informações que permitem o indivíduo formar suas convecções acerca do mundo. No caso do Jornalismo Científico, ele é embasado em "verdades" científicas. Quem atribui esse valor de verdade para o leitor são as fontes e também o próprio veículo de informação, já que a revista tem credibilidade porque busca sempre a exatidão dos fatos. Para isso ouve fontes autorizadas. As hipóteses são questionadas pelos cientistas para que os resultados sejam divulgados pelos periódicos.

\subsection{Poder de fala}

A interdição da fala é característica da nossa sociedade, em que não se pode dizer tudo, nem qualquer um pode falar de qualquer coisa. $O$ poder de fala está restrito a alguns, só eles têm esse direito privilegiado. Segundo o autor, em nossa sociedade, essa interdição está mais acirrada nas regiões da sexualidade e política. "É como se o discurso, longe de ser esse elemento transparente ou neutro no qual a sexualidade se desarma e a política se pacifica, fosse um dos lugares onde elas exercem, de modo privilegiado, alguns de seus mais temíveis poderes" (FOUCAULT, 2011, p.10).

Foucault (2011) quando relata a interdição da fala, faz uma analogia com o louco, cujo discurso não pode circular com o dos outros, já que sua palavra não tem verdade e nem importância para a sociedade, anulando o seu direito, como indivíduo, de lutar pelos seus direitos, já que também não tem voz perante a Justiça. Trazendo para o objeto de estudo analisado, as fontes convocadas a falar no discurso científico são aquelas que têm credibilidade, que falam a partir de instituições que têm respaldo perante a sociedade, como professores e pesquisadores, ou que a profissão da fonte dê voz a ela, como médicos e cientistas. A interdição desse discurso pode ser entendida como uma forma de passar credibilidade para os leitores, que eles vejam aquele texto como "verdade", mesmo que a linguagem seja acessibilizada, ou seja, sem termos científicos.

Já a noção de "autoridade" refere-se ao fato de o locutor proferir falas pelas quais ele não se responsabiliza, passando esse papel para um "locutor superlativo”, que garante a validade do enunciado. Esse enunciado é, geralmente, já conhecido pela sociedade, mas que não pode ser resumido ou reformulado.

Diante disso é possível perceber que o discurso jornalístico é polifônico. 
Por ele circulam diversas vozes: as fontes de informação, o jornalista que assina o texto, o leitor, a empresa jornalística e sua linha editorial, etc. Para que essas vozes tenham o poder de fala, o sujeito deve ocupar um lugar de fala, ou seja, de onde ele deve falar dentro daquele contexto. Segundo Lago e Benetti (2010), esses lugares são construídos fora do discurso em questão, eles são determinados pelas questões culturais, sociais e históricas, ou seja, o "externo" é que decide a materialidade discursiva.

No Jornalismo, esse locutor superlativo pode ser identificado como a fonte primária, que são as vozes convocadas para validar um discurso ou contrapor uma argumentação. Em um discurso, está embutido a representação de mundo de quem fala. Diante disso, a perspectiva de mundo que prevalece são das vozes que têm poder de expressão, ou seja, que pode colocar para a sociedade os seus ideais, interpretações e visão, já que elas têm uma posição diante da sociedade.

Esse fato foi muito notado no objeto analisado. As fontes que têm direito de fala nas reportagens, são todas renomadas e respeitadas pela sociedade. Isso dá sustentação e credibilidade ao que está sendo dito pelo autor do texto, pois é através dessa fonte primária de "poder" que os leitores vêem naquele texto a verdade. Para compreender melhor a força dos atributos das vozes autorizadas, recorremos à Pierre Bourdieu (1998) que define a utilização do nome próprio no mundo social. Para o autor, o processo de "nominação" institui uma "identidade social constante e durável, que garante a identidade do indivíduo biológico em todos os campos possíveis onde ele intervém como agente" (Idem, p.186).

O nome próprio é, portanto, atestado visível da identidade de seu portador através dos tempos e dos espaços sociais. É a forma por excelência da imposição e manifestação de um curriculum vitae, ficha judicial, necrologia ou biografia, etc., marcas que constituem um sentido de identidade (BOURDIEU, 1998). Em outras palavras, o nome próprio, esse "designador rígido", apresenta as propriedades sociais e biológicas de agentes sociais autorizados a falar, por serem detentores de determinado conhecimento especializado. Os jornalistas, por sua vez, apropriam-se das vozes autorizadas como forma de acessibilizar a informação científica.

Para esta análise, foram selecionados 26 exemplares de cada revista, publicados ao longo dos anos de 2011 e 2012. Inicialmente, é possível perceber que, durante todo o discurso das revistas Superinteressante e Galileu, os jornalistas buscavam fontes para validar ou tornar credível para os seus lei- 
tores aquilo que estava sendo dito nas matérias. Nas 26 matérias da revista Superinteressante, 144 fontes foram pronunciadas, sendo que $121(84,02 \%)$ foram fontes especializadas (Gráfico 1), ou seja, aquela pessoa que tem um saber específico de um determinado assunto (SCHMITZ, 2011).

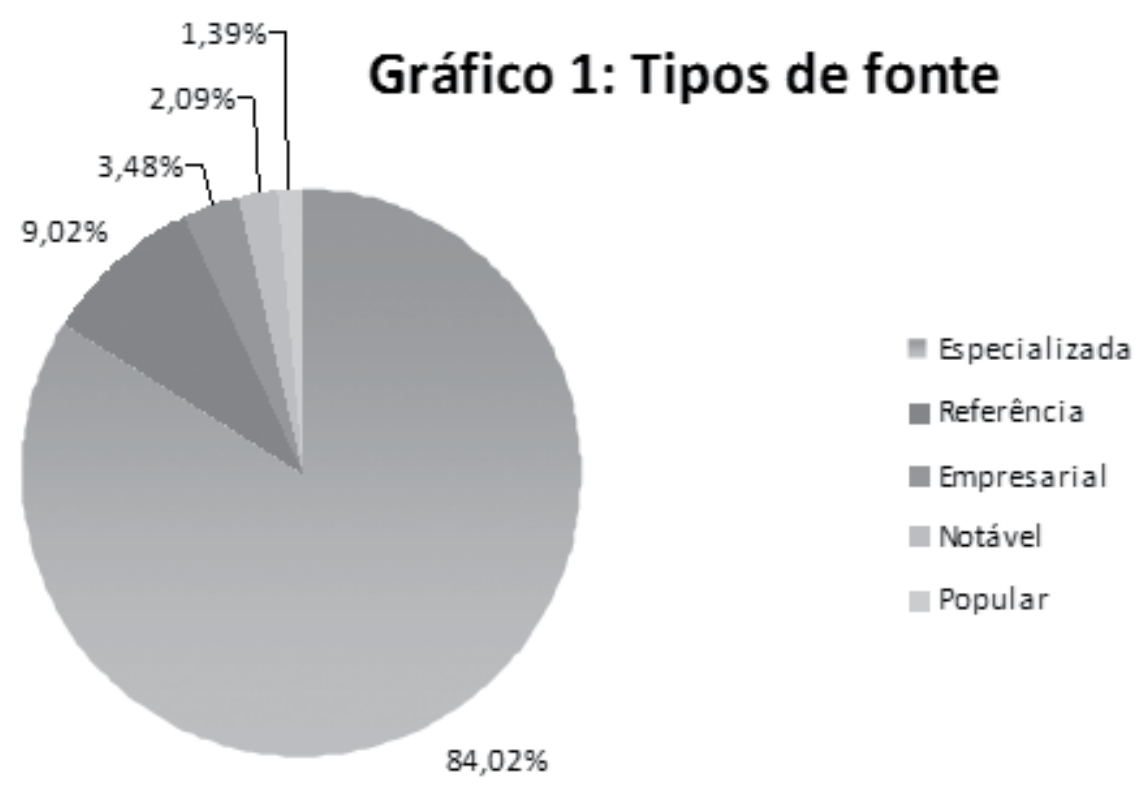

Gráfico 1: Superinteressante, tipos de fonte

Nas matérias analisadas da revista Galileu, foram totalizadas 198 fontes. Desse total, 148 (74,75\%) são fontes especializadas (Gráfico 2). Assim, é possível perceber que todas as matérias de capa analisadas nas duas revistas apoiaramse no depoimento de especialistas ou fontes creditadas a falar profundamente sobre o tema em questão. Isso porque as vozes autorizadas agregam valor de verdade ao discurso relatado, no caso o discurso científico das revistas.

\section{Gráfico 2: Tipos de fonte}

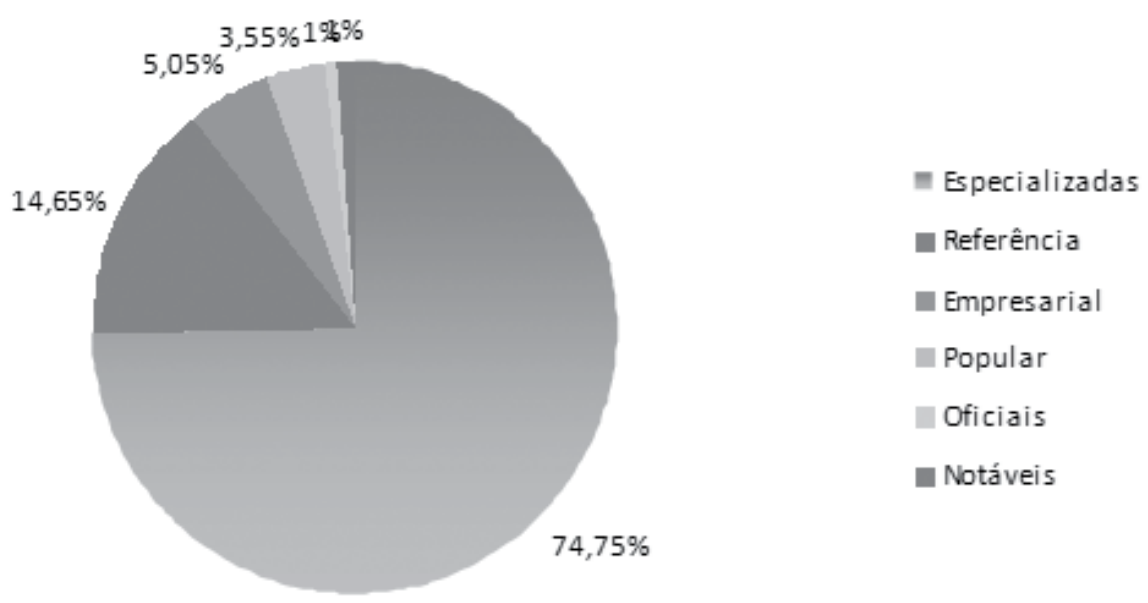

Gráfico 2: Tipos de fonte da Galileu 
Além das fontes serem, em sua maioria, especializadas, foi possível observar também o grande número de convocação de fontes estrangeiras nas reportagens dos dois periódicos. Dentro da classificação na revista Superinteressante, foram contabilizadas 75 fontes $(61,98 \%)$, geralmente de universidades dos EUA e Europa. Com relação às fontes brasileiras, foram totalizadas apenas $28(23,14 \%)$ e somente 18 (14,88\%) não foram classificadas. As fontes nacionais geralmente são de universidades, principalmente da Universidade de São Paulo (USP), Universidade Estadual de Campinas (Unicamp), Universidade Federal do Rio de Janeiro (UFRJ) e Universidade Federal do Rio Grande do Sul (UFRS). Tal fato, permite-nos questionar se as nossas universidades e centros de pesquisa não estão aptos a falar ou não são vistos como fontes seguras e de credibilidade (Gráfico 3).

\section{Gráfico 3: Fontes estrangeiras e nacionai:}

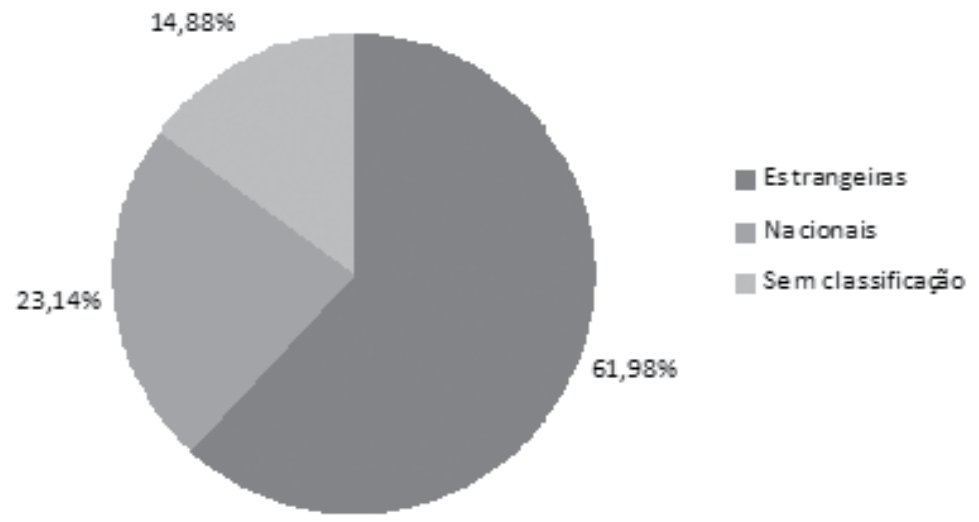

Gráfico 3: Superinteressante, origem das fontes

Na revista Galileu, com relação à origem das fontes, mais uma vez as estrangeiras prevaleceram. Destas, foram contabilizadas 108 (54,55\%) fontes, enquanto que as nacionais foram apenas 46 (23,23\%). Outras $44(22,22 \%)$ não foram especificadas (Gráficos 4).

\section{Gráfico 4: Fontes estrangeiras e nacionais}

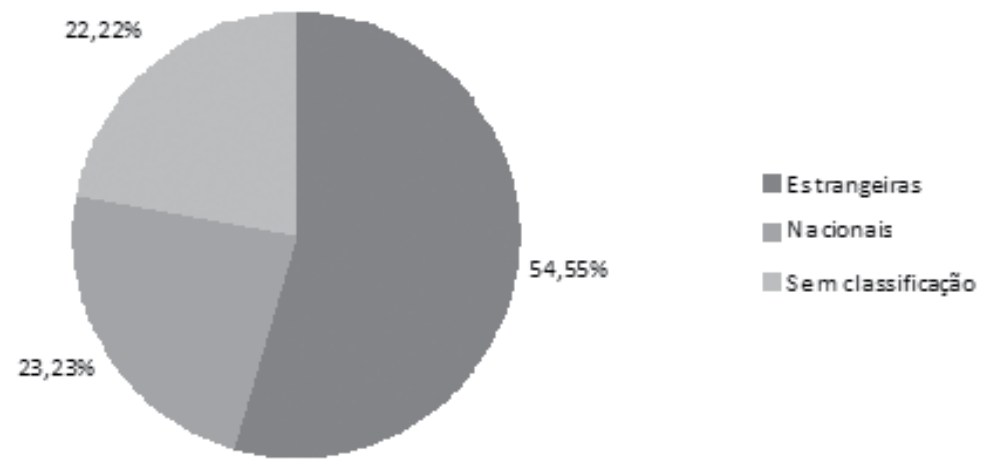

Gráfico 4: Origem das fontes da Galileu 
Segundo Beatriz Marroco (2013, p.119), "a entrevista potencializa a aproximação dos leitores à figura do intelectual, que ocupa um lugar soberano na posição formal de entrevistado". Além dessa aproximação, a fala do entrevistado é que dá valor de verdade à matéria, e, portanto, à revista. Assim, há uma grande importância nas fontes específicas ou especializadas, chamadas por Foucault de "intelectual específico", pois ocupam uma posição peculiar, cuja especificidades estão ligada às verdades que existem na sociedade. Segundo Foucault,

o problema político essencial para o intelectual não é criticar os conteúdos ideológicos que estariam ligados à ciência ou fazer sua prática científica ser acompanhada por uma ideologia justa, mas saber se é possível constituir uma nova política de verdade. Não se trata mais de mudar a "consciência" das pessoas ou o que elas têm na cabeça, mas alterar o regime político, econômico, institucional de produção da verdade, com a urgência e o gosto do agir próprio da febre, que cresce para intervir nas lutas, infleti-las ou modificá-las e um "desprezo soberano pela metafísica e pelos seus embaraços resíveis" (FOUCAULT citado por Beatriz Marroco, 2013, p. 121).

Dessa forma, nas mídias jornalísticas, o discurso da fonte é colocado como o "discurso da verdade" e a "entrevista nas mídias jornalísticas como o gênero discursivo da "voz e da autenticidade" (Sarlo, 2010, p.13 citado por Marroco, 2013, p. 122). Ali, entrevistado e o entrevistador estão unidos pelo contrato da verdade, ou seja, a fonte é procurada para autenticar o discurso de verdade "vendido" pelas mídias, no caso, pelas revistas. Os periódicos analisados têm como meta divulgar descobertas e verdades sobre acontecimentos exóticos e curiosidades de qualquer ramo do conhecimento, dando mais ênfase a temas relacionados à ciência. Buscam, assim, um reconhecimento da sociedade científica. Então, para que esse reconhecimento seja efetivado, é preciso que a revista passe credibilidade para o seu público e para isso é preciso utilizar um discurso consistente, convincente e credível.

Apesar desse discurso vir das fontes especializadas, o dispositivo de autoridade é atribuído à revista, ou seja, os leitores dão credibilidade à revista, já que a chamada se atribui ao nome da revista e não à fonte, mesmo que a verdade dita no discurso seja de autoria de um especialista. Isso pode ser visto em "Superinteressante selecionou os melhores especialistas para falar desse assunto" (edição 235). 
Outra estratégia utilizada pelos jornalistas como forma de se apropriar do discurso das fontes e, consequentemente, tornar o assunto mais próximo dos leitores foi o discurso direto, em que o entrevistador redigia fielmente a fala do entrevistado entre aspas também como um modo de tornar o discurso mais credível. Nesse discurso, o diálogo explícito é tão importante na medida em que os conceitos emitidos pela fonte de informação são de tal peso que sobressaem ao narrador indireto.

Das 144 fontes ouvidas na revista Superinteressante, 123 foram utilizadas como citação direta, como por exemplo em "O problema é quando a interação entre os funcionários se limita a falar mal do chefe", diz o psicólogo Tom Rath, do Instituto Gallup" (Superinteressante, edição 287, p.55). Na revista Galileu, o uso do discurso direto também prevaleceu: 198 fontes foram utilizadas, sendo que 184 foram convocadas diretamente em 15 matérias (62,4\%). Como exemplo podemos observar em "Não se pode acreditar em tudo que vemos", diz o psiquiatra Marcos Aurélio da USP” (Galileu, edição 244, p. 43). Assim, fica clara a preferência nas duas revistas pelo discurso direto da fonte, seja como forma de convencer o leitor ou até de passar credibilidade.

\section{CONCLUSÃO}

A partir da análise de Galileu e Superinteressante, foi constatado que as revistas trabalham com Jornalismo Científico. A partir da diferenciação deste conceito com a noção de Divulgação Científica e, considerando a análise das matérias de capa, notou-se que as revistas propõem-se a divulgar a ciência e transmitir conhecimento científico para fora do seu campo da comunidade científica, além de abordar de forma acessível para diversos públicos o que é tratado pela temática, tentando atingir não somente o público dos estudiosos ou entendedores do assunto.

Este artigo também se propôs a identificar as vozes autorizadas a falar na construção do discurso das reportagens de capa das revistas. Diante do que foi colocado, é possível perceber que as revistas usam estratégias para que esse conteúdo torne-se acessível e credível para os leitores a partir da convocação de fontes especializadas nos assuntos abordados. Além dessa marca de autoridade atingir os leitores, ela também é importante para o ethos da revista, pois é através de um discurso que ela se torna referência no mercado e adquire credibilidade entre os seus concorrentes. Para isso, ela também usa a fonte especializada.

A metodologia escolhida foi essencial para alcançar respostas que mo- 
tivaram esta análise. A Análise de Conteúdo e a Análise Crítica do Discurso auxiliaram na quantificação da recorrência das fontes no corpo de texto das reportagens e, também, no entendimento da função que o discurso direto exerce no que tange à veracidade e credibilidade das informações.

Alguns resultados obtidos com a pesquisa são importantes ressaltar. Entre eles, o fato das fontes autorizadas serem, em sua maioria, estrangeiras. Isso nos faz questionar se as universidades ou centros de pesquisas nacionais não têm respaldo diante dos leitores ou das próprias revistas, sendo preciso buscar fontes fora do nosso país. Notou-se também que, mesmo quando elas são nacionais, localizam-se, em sua maioria, no Sul e Sudeste do Brasil. Isso pode ser justificado já que os grandes centros de pesquisa e as Universidades que movem estudos ligados à Ciência e Tecnologia localizamse nessas regiões. No entanto, há instituições em outras regiões do país que desenvolvem pesquisas científicas, mas, que, por não serem os centros de referência no país, não são procuradas para tratar desse assunto.

E, por fim, o trabalho trouxe contribuições para a pesquisa em comunicação com a escolha da metodologia porque ela permitiu que o olhar do pesquisador buscasse as marcas de intencionalidade explícitas e implícitas nas matérias analisadas, entendendo as vozes que compõem os enunciados e compreendendo seu uso na composição do texto de divulgação científica. Para isso, foram utilizados os conceitos de verdade e poder de fala como ferramentas que guiam a busca de elementos intencionais nos textos.

\section{REFERÊNCIAS}

BENETTI, Marcia. Metodologia de Pesquisa em Jornalismo. 3. ed. Petrópolis- Rj: Vozes, 2010. 286 p. (Coleção Fazer Jornalismo).

BENETTI, Marcia; STORCH, Laura; FINATTO, Paulo. Jornalismo de revista, meta-acontecimento e dispositivo de autoridade. In: LEAL, Bruno Souza; ANTUNES, Elton; VAZ, Paulo Bernardo. Jornalismo e Acontecimento (orgs.). Florianópolis: Insular, v.2, 2011.

BOAS, Sergio Vilas (Org.). Formação e Informação Científica:jornalismo para iniciados e leigos. 3. ed. São Paulo: Summus, 2005. 92 p.

BOURDIEU, Pierre. A ilusão biográfica. In: AMADO, Janaína; FERREIRA, Marieta de Moraes (orgs.). Usos e abusos da história oral. Rio de Janeiro: Editora da Fundação Getúlio Vargas, 1998.

FOUCAULT, Michel. A ordem do discurso: aula inaugural no Collège de France, pronunciada em 2 de dezembro de 1970. 19ª.ed.Edições Loyola, São Paulo. 2009 a.

GRILLO, Sheila. Divulgação Científica na Esfera Midiática, 2006. Revista Intercâmbio, volume XV. São Paulo: LAEL/ PUC-SP. Disponível em [http://www4.pucsp.br/pos/lael/in- 
tercambio/pdf/grillo.pdf] Acessado em 14 de janeiro de 2013

MARROCO, Beatriz “A palavra dos intelectuais da mídia”. TAVARES, Frederico; SCHWAAB Reges (org.). A revista e seu jornalismo. São Paulo: Penso, 2013. 303 p

SCHMITZ, Aldo Antônio. Fontes de Notícia: ações e estratégias das fontes no jornalismo. Florianópolis: Combook, 2011.

KREINZ, Glória; PAVAN, Crodowaldo (Org.). Os donos da paisagem: estudos sobre divulgação. 21. ed. São Paulo: Njr, 2000. 252 p. (Coleção Divulgação Científica III).

\section{Catarina Schneider}

Jornalista. Mestranda do Programa de Pós-Graduação em Comunicação Social na linha Cultura, Narrativas e Produção de Sentido da Universidade Federal de Juiz de Fora (UFJF).

\section{Michele da Silva Tavares}

Jornalista. Especialista em Comunicação Digital, pela Faculdade de Administração e Negócios de Sergipe (FANESE). Mestre em Comunicação e Cultura Contemporâneas (UFBA). Doutoranda do Programa de Pós-Graduação em Comunicação Social da Universidade Federal de Minas Gerais (UFMG), vinculada à linha de pesquisa "Textualidades Mediáticas". 